\title{
Economic effect of corona pandemic on Saudi pro league football tournament (Applied in Saudi Pro League)
}

\author{
Yousef AlThobaiti \\ Faculty of Physical Education Dept. Collage of Education. Umm Al-Qura University, Kingdome of \\ Saudi Arabia \\ Email: yathobaiti@uqu.edu.sa
}

\section{Received: 05 October 2020; Revised: 03 March 2021; Accepted: 27 April 2021 \\ 3. https://doi.org/10.24036/ MensSana.06012021.23}

\begin{abstract}
The study aims to identify economic effects of Corona pandemic on Saudi football represented in SPL sector, and precautionary measures to reduce these effects on Saudi football. the researcher used the descriptive approach (survey studies), and the study sample was (75) academics specialists in sports administration and experts in the field of sports economics, and officials in the different sectors of SPL. There are negative effects of the Corona pandemic on the Saudi football sector, but also it has a positive impact that is to try to activate online management and virtual training, while the negative economic effects on players, administrators, clubs and the professional league's revenues increase as the time of the pandemic continues. The Saudi footballer should have a plan to work online in case of natural disasters, and put a term in the contracts in the sports field In case of natural disasters that lead to the cancellation of a sporting event before its establishment, its postponement or non-completion, the method of termination of the contract shall be determined according to each case, with the activation of the role of online training in the association and sports clubs, and the activation of the role of electronic services.
\end{abstract}

Keywords: Sport Economics-football-corona pandemic-SPL

\section{INTRODUCTION}

Natural disasters cause many negative effects on different sectors (economic / social / ... etc.) for the country, region or the whole world according to the scale of the disaster, and the world is currently exposed (the first quarter of 2020) to one of the natural disasters (Corona pandemic) as Many questions have been raised about the impact of its spread as one of the natural disasters that the countries of the world, including Saudi Arabia, are going through on the economy (investment / tourism / trade / health / energy / sports / ..... etc.) and future expectations, on both short or long term, and so we find that most of the expectations are negative for most economic sectors, including the sports sector.

Natural disasters are horrific events that infect a sector of community or the entire community with severe risks and material and human losses, and lead to confusion, imbalance and deficiency in the various organizations in the speed of preparation for confrontation, and so chaos in performance and conflict of roles at various levels .(Kamel,1993)

According to the above, the researcher has found that the Corona pandemic represents one of the worst natural disasters that strikes the world, such as (the floods in China (1931) / the cholera epidemic (1947) / the Indian Ocean tsunami (2004) / the Ayvialaikl volcano in Iceland (2010) / the fires of Australia (2020) / ... etc.).

Whereas, the World Health Organization announced on (3/11/2020) the SARS-cov-2 virus, one of the corona viruses that causes Covid-19 disease, a global pandemic (pandemic) due to the rapid spread of the infection and its wide scope in the world (www.who.int).

Sports organizations depend mainly on "self-revenues" that result from the organization's investment (such as name / logo / shirt ... etc.). With some simple effort, these organizations can obtain a sponsor (partner) for their sports activities, and because of the suspension of training and Sports activities and tournaments as a natural result of facing the Corona pandemic, most 
sports organization economies will be affected as a result, the revenues resulting from television broadcasts, sponsorship rights, match tickets, the sale of sports products ...and others will necessarily decrease (WEForum.org).

And soon the global sports economy was affected by the repercussions of the spread of the Corona virus, as it began through (postponing some matches in some European leagues / holding some matches without fan attendance / .... etc.) and then the situation developed with the escalation of the virus spreading to (suspending sports activity in Most countries in the world / suspending all local competitions / postponing the thirty-second Summer Olympic Games Tokyo (2020) / postponing European Football Cup (Euro 2020) for a yea / postponing Copa America (2020) for a year / postponing African Nations Cup qualifiers (2021 AD) / postponing the Asian qualifiers for the FIFA World Cup in Qatar (2022 AD) / ... etc.)

Then the situation developed into the cancellation of many sports events (exhibition and cycling race in Dubai / European Karate Championship in Azerbaijan / Indian Wells tennis tournament in California / Asian Weightlifting Championship in Uzbekistan / Wimbledon Tennis Championship / ... etc.), and the situation until the preparation of this research report warns of the possibility of not being able to complete many sports events (the league competition in a large number of countries / UEFA Champions League / F-Champions League Africa / ... etc.).

Soccer is considered one of the first popular sports in the Kingdom of Saudi Arabia, and the SPL represents an important sector as the league consists of 16 clubs according to the association's rule, and what this sector represents from clubs, players, referees, coaches, administrators, and fans. This what makes a direct or indirect connection between these categories within this wide sector, which represents a large part of the soccer ball in the Kingdom of Saudi Arabia, represented by the Prince Mohammed bin Salman League and the Prince Mohammed bin Salman Cup.

So that all the Kingdom's clubs try to be from the 16 clubs Members of the Association for the special sponsorship and support that these clubs enjoy, whether at the technical level or the marketing level for the players through the professional contracts concluded by companies related to sports business in the Kingdom. and given to the association's contribution to the support process for clubs and players which achieves the association's goals of developing football At the Kingdom level and global level, there are standards, policies, and regulations that govern the association and clubs participating in the association, as well as football referees and the Saudi Arabian Football Association (policies of SPL)

The Saudi Pro League ( SPL) is considered one of the organizations affected by the suspension of training, activities and sports tournaments due to the Corona pandemic, as the SPL relies on the revenue from marketing rights and commercial contracts - on the support from the federation in accordance with Article 30 of the League's Basic Regulations The Saudi Pro League, which distributes $40 \%$ of the revenues of these contracts to the clubs participating in the League, thus stopping the work of (trainers / administrators / referees / specialized technical committees / workers / selling products and tools / .. and others) and as a result of this suspension the economies of The Saudi Pro League was affected, where the revenues resulting from television broadcasting, match tickets, and the sale of sports products ... etc. have decreased significantly due to the suspension of sporting activity in the Kingdom as well as in Asia.

So far, only a few studies have dealt with the effects of the COVID-19 pandemic on sports in general and on professional soccer in particular.

Through the factors reviewed by the researcher about the spread of the Corona pandemic and what it caused to the countries of the world, including the Kingdom of Saudi Arabia, with regard to its impact on the sports economy, it is important to study the economics of dealing with the Corona pandemic, and try to identify the costs, returns and risks resulting from the resumption or the continuation of the suspension of Training, activities and sports tournaments, and trying to deal with and overcome the crisis with the least possible coasts on the SPL sector.

\section{Research aims}

The research aimed to determine the economics of dealing with the Corona pandemic "by applying to the SPL sector" by identifying:

1- Dimensions of the impact of the Corona pandemic on the SPL sector.

2-The cost (financing / burdens) of dealing with the Corona pandemic on the SPL sector.

3-The return (direct / indirect) of dealing with the Corona pandemic on the SPL sector. 
Jurnal ilmiah Bidang Pendidikan Olahraga

Edisi November

Volume 6, Nomor 1, Tahun 2021: 84-91

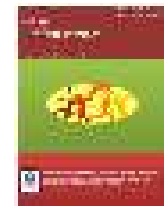

4 -The potential risks of dealing with the Corona pandemic to the SPL sector.

\section{Search questions}

1. What are the dimensions of the impact of the Corona pandemic on the Saudi Pro League sector?

2. What is the cost (financing / burdens) of dealing with the Corona pandemic on the SPL sector?

3. What is the return (direct / indirect) of dealing with the Corona pandemic on the SPL sector?

4. What are the potential risks of dealing with the Corona pandemic to the SPL sector?

\section{METHOD}

The researcher used the descriptive approach, surveys, analytical studies and case study, as this was more appropriate to the nature of the research and its problem. The research community included the SPL sector, (SPL, Sports Clubs), members of the association participating in the sports season tournaments 2019 / 2020. it also included experts in the field of sports, sports management, sports economics, sports crisis management, and specialists in the faculties and departments of physical education, where the researcher chose the research sample in the intentional method, and it reached (75) individuals' total sample, divided into two categories.

The first (30) individuals among a group of Academic experts who have a $\mathrm{PhD}$ in physical education and sports, sports administration or sport with its various specializations, the second of (45) individuals of coaches and administrators working in the field of football sport.

The researcher used the questionnaire as a tool to collect data, in the measurement process, and the validity of the questionnaire was verified using the validity of the content as well as the reliability of the questionnaire using the Cronbach's Alpha coefficient in the period from $1^{\text {st }}$ till $7^{\text {th }}$ June 2020 , then the researcher conducted the questionnaire after the verification of the scientific procedures ( validation - reliability), where the questionnaire was applied in its final form by using the electronic design of the questionnaire form on Google Forms at the following address "https://forms.gle/HJnmCBB2Bxvpsdg36", on the basic sample of the research of (75) individuals in the period from $8^{\text {th }}$ till $25^{\text {th }}$ June 2020.

The researcher used SPSS statistical program, version 26, and used the following process: Average, standard deviation, Pearson correlation coefficient, Cronbach's Alpha coefficient. Frequencies and percentages. Chisquare test.

\section{RESULTS AND DISCUSSION \\ Research result}

Table (1) First axis" the most important

dimensions of the impact of the Corona pandemic on the SPL sector"

\begin{tabular}{ccccc}
\hline Phrase & Estimated & RI\% & Chi2 & Rank \\
\hline 1 & 352 & 93.87 & ${ }^{*} 226.90$ & 1 \\
2 & 339 & 90.40 & ${ }^{*} 116.43$ & 2 \\
3 & 325 & 86.67 & ${ }^{*} 40.28$ & 3 \\
4 & 274 & 73.07 & ${ }^{*} 55.27$ & 6 \\
5 & 283 & 75.47 & ${ }^{*} 116.07$ & 5 \\
6 & 313 & 83.47 & ${ }^{*} 87.12$ & 4 \\
Total & 1886 & $83.82 \%$ & & \\
\hline
\end{tabular}

$\mathrm{Chi}^{2}(5)=11.070 P=0.05 \%$

The results of Table (1) indicated that There are statistically significant differences between the responses of the research sample in the phrases of the first axis. and the order of the phrases is as follows: suspending exercises and activities came in first place by $93.87 \%$, then Declining the technical level of the players by $86.67 \%$, then Abandoning some workers (coaches / administrators / workers ... and others) in the SPL sector by $75.47 \%$, and Fans losing interest in the clubs by $73.03 \%$.

Table (2) Second axis, "1 ${ }^{\text {st }}$ indicator the most important costs (financing / burdens) of resuming the SPL sector"

\begin{tabular}{ccccc}
\hline Phrase & Estimated & RI\% & Chi2 & Rank \\
\hline 1 & 359 & 95.73 & $150.27^{*}$ & 2 \\
2 & 360 & 96.00 & $219.32^{*}$ & 1 \\
3 & 355 & 94.67 & $208.12^{*}$ & 3 \\
4 & 353 & 94.13 & $265.95^{*}$ & 4 \\
5 & 335 & 89.33 & $95.80^{*}$ & 6 \\
6 & 340 & 90.67 & $84.76^{*}$ & 5 \\
Total & 2102 & 93.42 & & \\
\hline
\end{tabular}

$\mathrm{Chi}^{2}(5)=11.070 P=0.05 \%$

There are statistically significant differences between the responses of the research sample in the phrases of the second axis, the first indicator. and the order of the phrases was as follows :Taking the mandatory health precautionary measures before the start of the SPL sector's training, 
activities and tournaments came in first place by $96.00 \%$, then Sticking to the precautionary measures specified by the relevant ministries, authorities and sports federations in this regard by $95.73 \%$, then Taking the mandatory health precautionary measures during training, activities and tournaments of the SPL sector by 94.67 ,then Taking the mandatory health precautionary measures after the end of the SPL sector's training, activities and tournaments by $94.13 \%$, then Basic expenses (salaries / stadium rent ... etc.) by $90.67 \%$. then Taking precautionary measures in the long term to face what is similar to the Corona pandemic in the future by $89.33 \%$.

Table (3) second axis, " $2^{\text {nd }}$ indicator: " The most important costs (financing / burdens) the continuation suspending of the training, activities and tournaments of the SPL sector with a decrease in revenues due to this suspension"

\begin{tabular}{ccccc}
\hline Phrase & Estimated & RI\% & Chi2 & Rank \\
\hline 1 & 305 & 81.33 & $85.44^{*}$ & 3 \\
2 & 283 & 75.47 & $50.33^{*}$ & 6 \\
3 & 300 & 80.00 & $66.96^{*}$ & 4 \\
4 & 314 & 83.73 & $116.64^{*}$ & 1 \\
5 & 287 & 76.53 & $107.72^{*}$ & 5 \\
6 & 309 & 82.40 & $165.60^{*}$ & 2 \\
Total & 1797 & 82.27 & & \\
\hline
\end{tabular}

$\mathrm{Chi}^{2}(5)=11.070 \mathrm{P}=0.05 \%$

There are statistically significant differences between the responses of the research sample in the phrases of the second axis, the second indicator. and the order of the phrases was as follows: The SPL sector has to implement remote training programs (online) came in first place by $96.00 \%$, then Rent playgrounds by $82.40 \%$, then Staff salaries for the SPL sector (full / deducted) by $81.33 \%$. then Training players in places inappropriate for training by $80.00 \%$, then Reducing the number of times of training per day in a way that is not compatible with the nature of football by $76.53 \%$, then Maintenance of playgrounds by $75.47 \%$.

Table (4) Third axis, " 1st indicator is the most important returns (direct / indirect) from the resumption of football training and tournaments of the SPL sector"

\begin{tabular}{ccccc}
\hline Phrase & Estimated & RI\% & Chi2 & Rank \\
\hline 1 & 335 & 89.33 & $* 185.59$ & 5 \\
2 & 343 & 91.47 & $* 131.48$ & 2 \\
3 & 338 & 90.13 & $* 138.27$ & 4 \\
4 & 327 & 87.20 & $* 158.92$ & 7 \\
5 & 342 & 91.20 & $* 124.28$ & 3 \\
6 & 352 & 93.87 & $* 156.67$ & 1 \\
7 & 334 & 89.07 & $* 177.84$ & 6 \\
\hline
\end{tabular}

\begin{tabular}{lll}
\hline Total & 2371 & 90.32 \\
\hline
\end{tabular}

$\mathrm{Chi}^{2}(5)=11.070 \mathrm{P}=0.05 \%$

There are statistically significant differences between the responses of the research sample in the phrases of the third axis, the first indicator. and the order of the phrases was as follows : Maintaining the classification of sports teams in the SPL Came in first place by $93.87 \%$, then Returning of players to their technical level by $91.47 \%$, then Increasing the ability to pay salaries for the SPL sector by $91.20 \%$.then Returning of coaches to their technical level by $90.13 \%$, then Reducing financial lost for football in the SPL by $89.33 \%$, then Reducing the chances of abandon some workers in the SPL sector by $89.07 \%$,then Activating the participation opportunities for sports club players by $87.20 \%$.

Table (5) Third axis, " $2^{\text {nd }}$ indicator is the most important returns (direct / indirect) "with a longterm economic impact after the end of the Corona pandemic" from the continued suspension of training and activities of the SPL sector.

\begin{tabular}{ccccc}
\hline Phrase & Estimated & RI\% & Chi2 & Rank \\
\hline 1 & 318 & 84.80 & $* 128.88$ & 11 \\
2 & 329 & 87.73 & $* 136.73$ & 9 \\
3 & 339 & 90.40 & $* 144.80$ & 4 \\
4 & 330 & 88.00 & $* 115.19$ & 8 \\
5 & 313 & 83.47 & $* 77.85$ & 12 \\
6 & 325 & 86.67 & $* 124.56$ & 10 \\
7 & 348 & 92.80 & $* 158.68$ & 1 \\
8 & 347 & 92.53 & $* 144.92$ & 2 \\
9 & 334 & 89.07 & $* 105.04$ & 6 \\
10 & 336 & 89.60 & $* 131.19$ & 5 \\
11 & 334 & 89.07 & $* 70.52$ & 6 \\
12 & 346 & 92.27 & $* 101.88$ & 3 \\
Total & 3999 & 88.87 & & \\
\hline
\end{tabular}

$\mathrm{Chi}^{2}(5)=11.070 \mathrm{P}=0.05 \%$

There are statistically significant differences between the responses of the research sample in the phrases of the third axis, the second indicator, and the order of the phrases was as follows : Applying electronic management to deal with such crises came in first place by $92.80 \%$, then Putting new ideas (uncommon / unconventional) to generate other sources of revenue when exposed to the Corona pandemic by $92.53 \%$, then Increasing health awareness and acquire healthy habits among athletes by $92.27 \%$.

Then Maintaining the safety of most members of the SPL sector from injury, even if there are some financial lost by 90.40 ,then Gain experience in dealing with similar crises and assessment of future risks by $89.60 \%$, then 
Directing thinking in activating the role of potential risk (crisis) management by $89.07 \%$,then Unify the efforts of sports organizations concerned in this regard in facing this pandemic by $89.07 \%$.

The possibility of developing appropriate plans to confront what is similar to the Corona pandemic in the future by $88.00 \%$,then Reducing the chances of the pandemic spreading among members of the SPL sector by $87.73 \%$,then Creating other (uncommon / unconventional) training methods for the home players by

$86.67 \%$, then Reducing the chances of any member of the SPL sector dying from this pandemic by $84.80 \%$, then Giving players a long break that they had never had before by $83.47 \%$.

Table (6) Fourth axis " $1^{\text {st }}$ indicator "The potential risks from resuming football training, activities and tournaments."

\begin{tabular}{ccccc}
\hline Phrase & Estimated & RI\% & Chi2 & Rank \\
\hline 1 & 302 & 80.53 & $115.20^{*}$ & 5 \\
2 & 309 & 82.40 & $114.97^{*}$ & 4 \\
3 & 310 & 82.67 & $110.92^{*}$ & 3 \\
4 & 329 & 87.73 & $104.85^{*}$ & 1 \\
5 & 328 & 87.47 & $154.27^{*}$ & 2 \\
Total & 1578 & 84.16 & & \\
\hline
\end{tabular}

$\mathrm{Chi}^{2}(5)=11.070 \mathrm{P}=0.05 \%$

There are statistically significant differences between the responses of the research sample in the phrases of the fourth axis, the first indicator, and the order of the phrases was as follows : Increasing the chances of infection transmission from the infected ones in contact with any member of the SPL sector (his family / friends / colleagues at work ... and others) came in first place by $87.73 \%$.

Then Fear of infection spread among members of the SPL sector by $87.47 \%$,then Increasing the probability of any member of the SPL sector to get infected with corona by 82.67 $\%$,then Increasing the chances of the pandemic spreading among the members of the SPL sector (SPL sector negligence in applying binding precautionary measures) $82.40 \%$, then Increasing the chances of deaths of any member of the SPL sector from this pandemic by $80.53 \%$.

Table (7) Fourth axis " 2 "nd indicator " Possible risks from the continued suspension of football training, activities and tournaments."

\begin{tabular}{ccccc}
\hline Phrase & Estimated & RI\% & Chi2 & Rank \\
\hline 1 & 268 & 71.47 & $68.87^{*}$ & 5 \\
2 & 333 & 88.80 & $68.92^{*}$ & 2 \\
3 & 325 & 86.67 & $95.71^{*}$ & 4 \\
\hline
\end{tabular}

\begin{tabular}{ccccc}
\hline 4 & 335 & 89.33 & $94.59^{*}$ & 1 \\
5 & 327 & 87.20 & $71.07^{*}$ & 3 \\
Total & 1588 & 84.69 & & \\
\hline
\end{tabular}

$\mathrm{Chi}^{2}(5)=11.070 \mathrm{P}=0.05 \%$

There are statistically significant differences between the responses of the research sample in the phrases of the fourth axis, the second indicator, and the order of the phrases was as follows : Some of the SPL sector has experienced financial problems that could reach bankruptcy Came in first place by $89.33 \%$, then Increasing players' weights by $88.80 \%$.

Players are accustomed to new patterns of comfort that do not match the nature of football training by $87.20 \%$, then The possibility of players experiencing psychological problems (depression / fear / panic ... etc.) by $86.67 \%$,then Retirement of some players by $71.47 \%$.

\section{Discussion}

The results of Table (1) indicates the most important dimensions of the impact of Corona pandemic on the Saudi football sport represented in the SPL from the decline in the technical, physical performance of the players of sports clubs members of the Association as a result of suspending sports activity due to the fear of Corona pandemic during training and among the public during the matches, and for that reason.

There is a positive relationship between the performance of the players on the field and the commercial returns of the club ( Szymanski,2013)( Brand,2011) the Saudi Arabian Football Association decided to suspend activity and consequently decrease in revenues, which resulted in major financial lost as a result of stopping the broadcast, and commercial rights, so the SPL decreased financial support which had a great impact on the member clubs.

The Association, and employees including coaches and administrators, as well as the tendency of some clubs to reduce expenses by abandon some workers or reducing their salaries, and how some disasters can change the public's tendency to support the club so as it help the club to resume activities during this sports season is consistent with what was mentioned in the study (Abu al-Nour And Taha, 2019) and (Bakhit,2019), (Bakhit,2018) that as a result of crises or natural disasters, sports federations and clubs try to rationalize expenses using many methods. 


\section{Economic effect of corona pandemic on Saudi pro league football tournament (Applied in Saudi Pro League) \\ Yousef AlThobaiti}

This consistent with what was mentioned in the Sports Business Institute report also indicated that sports lost due to the pandemic in the United States of America amounted to (5) billion dollars during March and April (2020), and the sale of tickets, privileges, sponsorship and broadcast rights represent the most important sources of revenue that will be affected (SBI,2020).

The results of Table ( 2 and 3 ) indicate that sports clubs, the Saudi Football Association and the Professional League have taken the necessary health precautionary measures before the start of training, activities and soccer tournaments, which necessarily requires costs (funding / burdens), the most important of which is to assure the presence of a thermal detector at the entrance / putting a path to sterilize shoes (sterilizing and disinfecting shoes upon entry) / sterilizing and disinfecting the hands of players / coaches / administrators / club workers / stadiums / tools / equipment ... etc.), and that such costs are borne by The Federation,

Professional Association, and Sports Clubs provide additional financial burdens to limit the spread of the Corona virus. This is mentioned in the results of the research (Muhammad \& Abdel Fattah, 2020), (Kerjan et al,2013) (Swanepoel, 2013) which indicated that sports clubs bear additional financial burdens to prevent the Corona virus inside their headquarters during training for players, the technical, and administrative staff.

The researcher believes that for the Professional League and the Saudi Football Association to implement remote training programs (online), necessarily costs (financing / burdens) are needed, with recognition of applying electronic management during the coming period, as consistent with the results of the research (AlShamikh, 2019),(Filo et al,2015), (Garrett,et al,2007) which indicated that electronic management is an inevitable process for dealing with (FIFA / AFC / Confederations / SPL / Specialized Technical Committees / Sports Clubs / Elements of the Game ... etc.). Sports clubs' employee salaries (full / deducted) in light of the continued suspension of football training, activities and tournaments, with low revenues due to this suspension, and that such costs add financial burdens on the Saudi football sector.

Tables $(4,5)$ indicate that the resumption of football training, activities and tournaments helps the football sector pay the salaries of its employees, and that is through the influx of financial resources as a result of this resumption. So if this suspension continue this sector will face a major economic problem represented in (needs and different and various targets).

This is as mentioned in the results of (Muhammad, 2015) research that the sports club has an economic problem facing it due to its needs. With the inevitability of applying electronic management to deal with such crises in the future. This is in line with the results of the research (Muhammad and Abdel Fattah, 2020), which indicated the activation of the role of electronic services (cards / fees / competitions ... and others) within the football sport sectors (Al-Shamikh, 2019) (1), with The need for the Saudi football sports sector to develop new ideas to obtain other sources of revenue when exposed to what is similar to the Corona pandemic, in order to cover all needs, desires and goals that are required to be satisfied or achieved.

This is as mentioned in the results of research by Pamela Wicker and others (Wicker et al, 2013), which indicated that clubs used human and financial resources in recovery efforts and that organizational flexibility, number of members, and the use of government grants had a significant positive impact on overall recovery.

For the club affected by natural disasters, the government grants, insurance coverage, and inter-organizational relationships are factors that helped clubs become more flexible (Kerjan et al., 2013). The results of Table $(6,7)$ indicated that there are many economic and psychological obstacles that prevent the implementation of disaster risk reduction laws in many countries, such as the high costs of disaster risk reduction measures in advance, misunderstanding of the risk and overconfidence in their ability to Survival during disasters plus difficulties in calculating the benefits of disaster risk reduction measures is consistent with. (Kerjan et al. 2013)

Also there is a significant decrease in the revenues of football sport organizations as a result of the continued suspension of football training, activities and tournaments, which clearly means the possibility of this football sector being exposed to financial (economic) problems that may reach bankruptcy represented in (Needs, different and various targets) (Muhammad, 2015).

Likewise, the potential risks of continuing the suspension are greater than The potential risks from resumption, which is natural and logical, because the return of competitive sporting activity and the previous practical exercises are necessary for football sport organizations, especially in the return of training in some competing countries, 
impact on helping the sector to survive such crises. necessity of sticking to the application of the precautionary procedures obligation when resuming football training, activities and tournaments, as the( safety of players, coaches.

Administrators, workers, and other members of the football sector that are directly related to the player) as their health necessarily affects the economies of the football sector after the resumption, as in case of the players gets infected by the disease, this clearly means that the economies of this sector are affected, which has spent on them, took care of them, and developed their technical, physical, health, mental and psychological levels ... and others through the training programs set for that.

This is as mentioned in the results of the research of (Muhammad, 2016 AD) that work time is the time available for production and achieving goals (completing work / performing tasks / performing duties) and that this time has a very large material cost, and therefore it was necessary to invest this time, Efficiently and effectively to ensure the effective economical operation of working time (the correct relationship between operating expenses and operating revenue - costbenefit relationship).

\section{CONCLUSION:}

In light of the objectives and problem of the study and within the limits of the research sample and previous studies, and the results of statistical analysis, the researcher reached the following conclusions:

1. Suspension of exercises and canceling the remaining matches of the 2019/2020 sports season came $1^{\text {st }}$ by $93,87 \%$ as a negative impact on the SPL sector.

2. The costs (financial $\backslash$ burdens) due to taking the mandatory health precautionary measures before the restart of the SPL sector's training, activities and tournaments came $1^{\text {st }}$ by $96 \%$ as a negative impact on SPL sector budget.

3. The SPL sector has to implement remote training programs (online) came $1^{\text {st }}$ by $96.00 \%$ as a positive impact on the continuation of the game.

4. Maintaining the classification of sports teams in the SPL came $1^{\text {st }}$ by $93,87 \%$ as a positive impact on the clubs in the SPL sector.

5. Applying electronic management to deal with such crises came $1^{\text {st }}$ by $92.80 \%$ with a positive
6. Fear of infection spread among members of the SPL sector came $2^{\text {nd }}$ by $87.47 \%$ with a negative impact on the training process on the field.

7. Some of the SPL sector has experienced financial problems that could reach bankruptcy came $1^{\text {st }}$ by $89,33 \%$ with a negative impact on the continuation of the season.

\section{Recommendations:}

Saudi sports sectors must adopt a set of precautionary measures to limit the economic impacts of natural disasters by using the set of precautionary measures. Sitting a guide for the application of "on line work" in the sports sectors and procedural guidance in emergency circumstances. The officials in charge of the Saudi sports sectors should create new ideas to reduce the size of economic lost.

Such as holding virtual matches, rebroadcasting archive matches, organizing tournaments using electronic games, marketing players for television advertisements. Paying attention to develop the skills of workers in sports organizations in the remote working (online). Every sports entity should create a fund called "risk fund" to be used during disasters. Paying attention to develop sports entities technologically.

\section{REFERENCES}

Abu El-Nour ,Ashraf Abdel-Moez Abdel-Rahim Mohamed- Bakhit, Taha Mahmoud Taha (2019): The economics of Egypt's approval to organize the 2019 Africa Cup of Nations (goals / cost / benefit / potential risks / economic operation), Scientific Journal of Physical Education and Science Sports, College of Physical Education for Boys, Helwan University, Issue 86, Part 3.

Brand Finance(2001): "Brand finance European football brands 2011", Brand Finance, London, UK.

Bakhit, Taha Mahmoud Taha(2019): Economic feasibility of organizing the Egyptian Football Association for the 2019 Africa Cup of Nations (costs / profits), , Scientific Journal of Physical Education and Sports 
Sciences, College of Physical Education for Boys, Helwan University, Issue 86, Part 3.

Filo, Kevin \& Cuskelly,Graham, Wicker, Pamela(2015): "Resource utilization and power relations of community sport clubs in the aftermath of natural disasters", Sport Management Review, Vol 18, Iss 4, P.P 555-569.

Garrett ,R. Kelly \& Danziger ,James N.(2007): "Which telework? Defining and testing a taxonomy of technology-mediated work at a distance", Social science computer review, Vol 25, No 1.

Kerjan,Erwann Michel- Stigler ,Stefan Hochrainer- Kunreuther, HowardLinnerooth, Joanne -Bayer, Reinhard Mechler, Robert Muir-Wood, Nicola Ranger, Pantea Vaziri, Michael Young(2013): "Catastrophe risk models for evaluating disaster risk reduction investments in developing Countries", Working Paper at Forthcoming in Risk Analysis, Risk management and Decision processes center, The Wharton school, University of Pennsylvania, Pennsylvania, USA.

Mohamed, Ashraf Abdel-Moez AbdelRahim(2016): Economics of Working Time Management for Employees of the Egyptian Football Association, The Scientific Journal of Physical Education and Sports Sciences, College of Physical Education for Boys, Helwan University, Issue 76,

Mohamed, Sherif El-Sayed Youssef, - AbdelFattah,Ahmed Sayed Ahmed(2020): The Economics of Egyptian Sports During Natural Disasters (Case Study, The Scientific Journal of Physical Education and Sports Sciences, College of Physical Education for Boys, Helwan University, Issue 89, Part 1.

Darwish, Kamal El-Din Abdel-Rahman, Muhammad Sobhi Hassanein(2004): "Encyclopedia of Sports Management Vectors at the Beginning of the New
Century", Volume 1 "Quality and Globalization in Sports Business Management Using New Administrative Methods", Arab Thought House, Cairo, Egypt.

Kamel, Abdul-Wahab Muhammad(1993): "The Psychology of Crisis Management", Dar AlFikr for Printing, Publishing and Distribution, Amman, Jordan,.

Swanepoel,M.J.(2016): "The correlation between player valuation and The bargaining position of clubs in the English premier league (EPL)", International journal of economics and finance studies, Vol 8, No 1. P.P 209-225.

Szymanski, Stefan(2011): "Commercial football and the Economic cycle", Optimal strategies in sports economics and management, Springer, Berlin, Germany, P.P 187-197. 